\title{
Experiences in Improving Efficiency of Energy and Other Resources in Metal Industries in Nepal
}

\author{
Amar B Manandhar ${ }^{1,}$ *, Durga B Karanjit ${ }^{1}$, Govinda Tiwari ${ }^{~}$, Gopal K Shrestha ${ }^{1}$, Deepsikha Byanju ${ }^{1}$, \\ Parashar K Deo ${ }^{1}$, Priyanka Karna ${ }^{1}$, Vikas Singh ${ }^{2}$, Ranu Pachauri ${ }^{2}$, Devesh Kumar ${ }^{3}$, Malini Balakrishnan ${ }^{3}$, \\ Stefan Melnitzky ${ }^{4}$ \\ ${ }^{I}$ Society for Environmental and Economic Development Nepal (SEED Nepal), 39 Siddharth Marg, Anamnagar, Ward \\ No. 29, Kathmandu, Nepal \\ ${ }^{2}$ STENUM Asia Sustainable Development Society, 315A Suncity Trade Tower, Sector 21, Gurugram 122016 India \\ ${ }^{3}$ The Energy and Resources Institute (TERI), Darbari Seth Block, India Habitat Centre, Lodhi Road, New Delhi 110003 \\ India \\ ${ }^{4}$ Austria Recycling, Wipplingerstrasse 5/8, 1010 Vienna, Austria \\ Corresponding Email: amar@seednepal.org, amar@metabuild-southasia.org
}

\begin{abstract}
:
The construction sector uses various metals like steel (for frames, reinforced concrete), iron (wrought iron for beams, trusses, girders), aluminium (ceiling and walls, window frames, HVAC systems etc.) and copper (cladding, electrical wiring, oil \& gas lines). Due to increasing pressure on various resources like energy, chemicals and raw materials, economic edge can be sustained only through high resource efficiency. Adopting resource efficient cleaner production (RECP) measures will improve economic and environmental performance, including reducing greenhouse gas emissions; in turn, this will make them less vulnerable to changes in external conditions and more competitive. With co-funding from the EU SWITCH-Asia Programme, the project METABUILD (www.metabuild-southasia.org) aims at implementing sustainable production processes and practices in 400 SMEs across Bangladesh, Nepal and Sri Lanka besides creating a conducive environment for further adoption of sustainable production processes in the metal products supply chain for the building and construction sector. In Nepal, the project has already engaged with 82 metal industries. These cover different sectors such as fabrication, wire drawing, electrical cables, re-rolling, galvanizing/electroplating, casting etc. and are in multiple locations viz. Kathmandu, Lalitpur, Morang, Sunsari, Rupandehi, Bara, Parsa, Kaski districts. RECP measures such as use of daylight, replacement of inefficient lights by LED lights, power factor improvement, furnace modification, waste heat recovery, insulation etc. have been implemented. These have led to savings in energy and raw materials, at the same time reducing generation of wastes from these participating industries and improvement of occupational health and safety (OHS). This paper will explain the mode of engagement with industries, details of the resource efficiency measures implemented and estimated saving.
\end{abstract}

Keywords: Metal Sector, Resource Efficient Cleaner Production (RECP), No Cost/Low Cost Measures, Resource Savings

\section{Introduction}

This paper is focused on metal companies most of them in the small and medium enterprises (SMEs) category that are part of the supply chain in the construction sector. The construction sector uses various metals like steel (for frames, reinforced concrete), iron (wrought iron for beams, trusses, girders), aluminium (ceiling and walls, window frames, heating, ventilation and air conditioning or HVAC systems etc.) and copper (cladding, electrical wiring, oil and gas lines). Steel is a key component of residential and commercial buildings due to its long life and recycle capability. In many developing economies, more than $60 \%$ of the steel is consumed to create new infrastructure. Steel products from re-rolling such as bars, sectional products are used in construction sector. The growth in construction sector is also linked to growth in tourism with requirement for more hotels. Tourism also impacts metal handicrafts production. In Nepal, the raw materials for metal based industries are primarily billets, sheets, wire rods, ingots and scraps. Thus, Resource Efficient Cleaner Production (RECP) in this sector can contribute significantly towards overall goal of sustainable buildings and tourism.

The metal processing industry is one of the most important sectors in Nepal. Iron and steel products are mainly for domestic use and some of these are also exported. 
Products identified for potential export by the Nepal Trade Integration Strategy (NTIS) include Galvanized Iron (GI) sheets, pipes and rolled iron bars. Due to Nepal's infrastructure development, domestic demand for metal products is increasing. Based on a 2012 study by GIZ [1], there is a significant potential for energy savings in this sector.

The need for adopting sustainable practices is spearheaded by customer demand for high quality and low cost, more stringent environmental standards and the costs incurred to meet them. So far, the focus of the industry in South Asia was on being competitive due to cheap and abundant labour, favourable exchange rates and concessional duty structure. However, due to increasing pressure on resources like water, energy etc., it is becoming clear that the economic edge can be sustained only by ensuring high resource efficiency. Specific problems include: lack of modernization, sub-optimal operation leading to inefficiencies, lack of technical and financial support for improving operations, lack of skilled manpower and traditional mind-set. These lead to poor economic and environmental performance, low profitability and therefore greater vulnerability to changes in external conditions and low competiveness.

With this background, the 4-year (2016-2020) project "Resource efficient supply chain for metal products in buildings sector in South Asia (METABUILD)" was initiated. This project is supported by the European Union SWITCH Asia Programme to promote sustainable consumption and production in Asia. The project, implemented by a consortium of seven institutions from Europe and Asia, aims at RECP implementation in 400 metal SMEs in Nepal, Sri Lanka and Bangladesh. This paper presents the experience of Nepal with the RECP measures that were implemented and the savings in energy and raw materials that were achieved.

\section{Methodology}

The methodology followed was adapted from the ECOPROFIT model developed in Graz, Austria in 1991[2,3,4]. The main components used in this project were individual company consulting by trained experts and workshops / trainings for participating companies.

The first step was to mobilize companies to join the project. This was done through a series of four management commitment seminars in various locations where senior members or owners from the companies were informed about the project and shown examples of benefits from RECP implementation in similar companies. As a result, 82 companies were inducted to participate in the project.

The project team in SEED-Nepal was initially trained on the ECOPROFIT approach and methodology by European and Indian experts. Newly recruited consultants were trained locally as well as regionally in India. The participating companies were visited by the trained team together with Nepalese senior consultants initially accompanied by international experts to carry out an initial assessment. The data for resource consumption was also collected. Based on the initial assessment visit and data, companies were provided with a list of implementation measures to address the inefficiencies observed. In discussion with the companies, the measures to be implemented were prioritized and a detailed action plan prepared for these measures to support implementation. The implemented measures were analysed to estimate the resource savings and economic benefits. Continuous engagement with the participating companies was maintained along with periodic trainings to motivate implementation of the prioritized RECP measures. Awareness trainings have been conducted for 32 participating companies inducting 915 persons. Similarly, seven RECP trainings have been conducted to train 113 persons from 48 participating companies to-date.

With a view to maximize benefits to the participating industries, other supporting activities are also being planned and conducted. These include developing financial linkages for investment required to implement RECP options, carrying out customer roundtables to generate customer awareness on greening the supply chain, exploring more efficient technology and knowhows through technology fair and for the establishment of long term strategy through policy dialogues.

\section{Results from RECP Implementation}

As of date 82 companies from various sectors (Figure 1) are actively participating in the project. The main sectors are fabrication, wire drawing, rolling/ re-rolling, cable making, foundry and galvanizing / electroplating. So far around 21 companies have implemented one or more RECP measures. Many of these are no cost or low cost measures with short payback periods. Some typical examples are described in the following sections.

\subsection{Example Case Studies:}


Table 1: Participating Industries

\begin{tabular}{|l|l|l|}
\hline S. No. & Sector & No \\
\hline 1 & Fabrication & 26 \\
\hline 2 & Wire Drawing & 15 \\
\hline 3 & Cable & 11 \\
\hline 4 & Rolling Mill & 14 \\
\hline 5 & Foundry & 8 \\
\hline 6 & Galvanizing, Electroplating & 8 \\
\hline & Total & 82 \\
\hline
\end{tabular}

\subsubsection{Curing Tank Insulation}

The case study company was an electrical cable manufacturing unit in Morang district. Two tanks with 16 $\mathrm{kW}$ electric heaters each were being used for curing. During the initial assessment visit, it was observed that the tanks were not insulated (Fig 2a). For each batch, the tanks were operated for 6 hours leading to consumption of $192 \mathrm{kWh}$ of electricity.

The intervention involved insulation of both tanks with glass wool which was further protected with metal

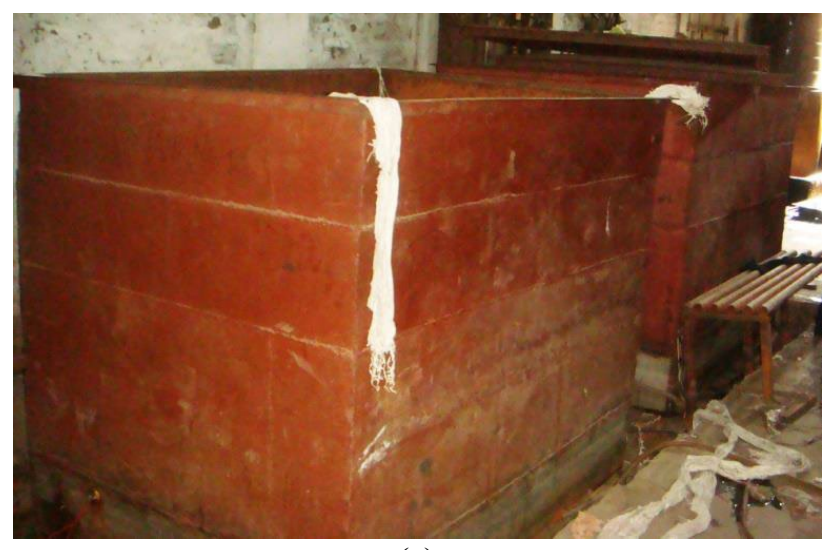

(a)

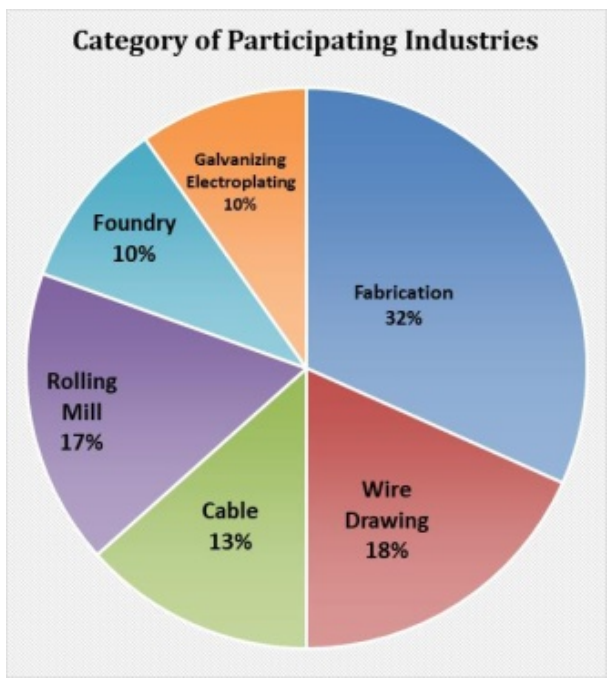

Figure 1: Categories of Participating Industries

cladding (Fig 2b). As a result of the insulation, the operation time per batch was reduced to 4 hours and the electricity consumption decreased to $128 \mathrm{kWh}$.

The investment made was Nepalese Rupees (NPR) 30,000 and the annual savings from electricity consumption reduction was NPR 102,400. The payback was around 3.5 months.

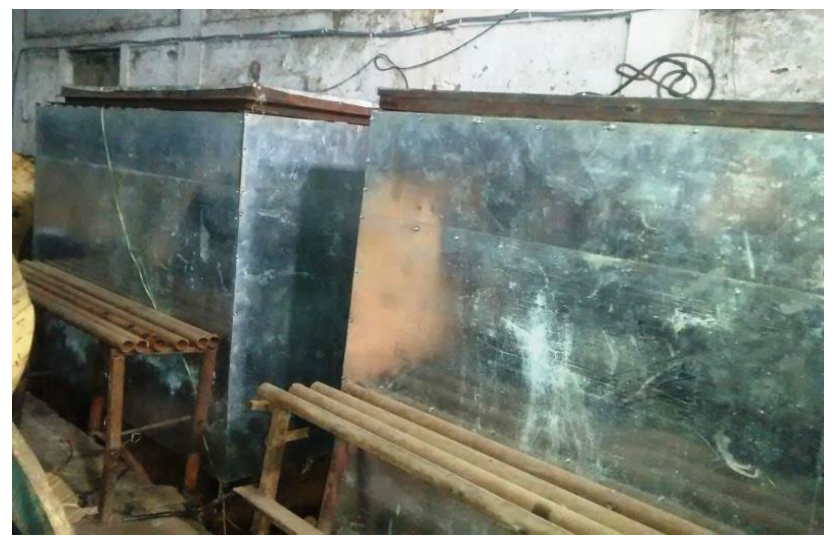

(b)

Figure 2: Curing Tanks (a) Before Insulation (b) After Insulation

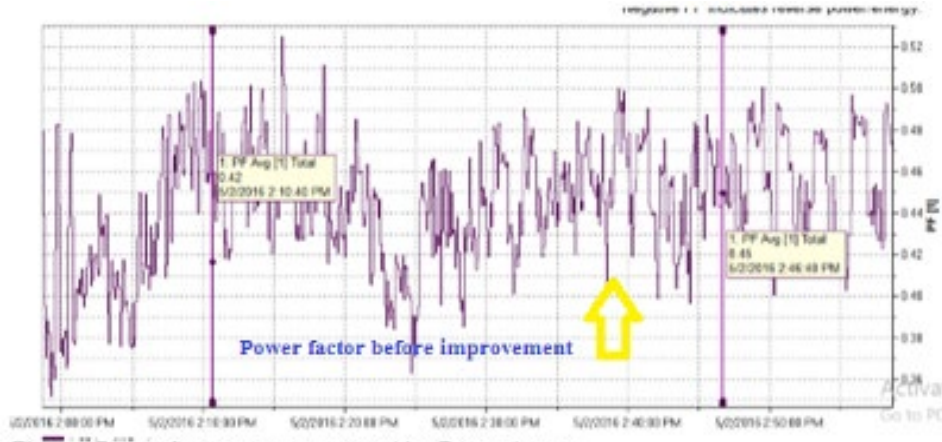

Figure: Power factor curve captured by Power logger

(a)

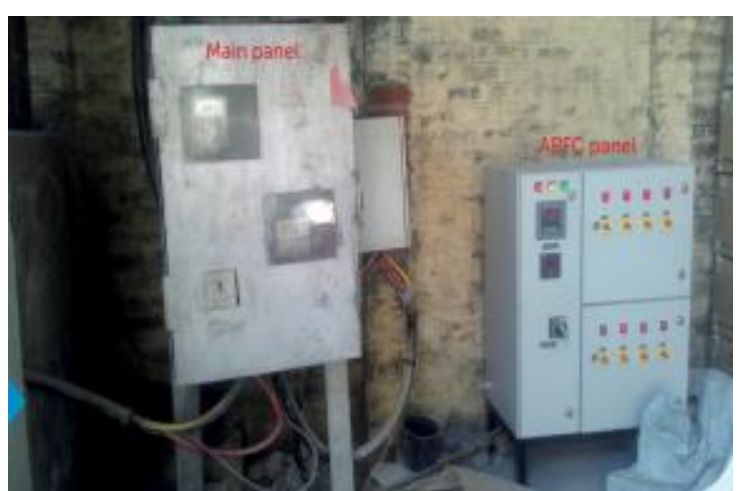

(b)

Figure 3: (a) Power factor values before intervention (b) Automatic Power Factor Controller 


\subsubsection{Power Factor Improvement}

The case study company was a fabrication and galvanizing unit in Rupandehi district. The power factor on an average was observed to be 0.48 (Fig 3a). The average chargeable demand was $121.9 \mathrm{kVA}$.

Based on recommendations, the company installed an Automatic Power Factor Controller (APFC) along with capacitor bank of $98 \mathrm{kVAr}$ in main panel (Fig 3b). This led to the power factor being maintained at 0.99 and the chargeable demand was reduced to $90.9 \mathrm{kVA}$.

The investment made was NPR 150,000 and the annual savings from chargeable demand reduction was NPR 93,000 . The payback was around 1.7 years.

\subsubsection{Optimizing Material Movement}

The case study company was a fabrication unit in Rupandehi district. The work pieces after drilling, grinding and other machining operations were kept on the floor (Fig 4a). In order to move the work pieces from one process to the next, a worker would carry them by hand.

Based on the recommendations, semi-finished pieces after drilling, grinding and other machining operations were

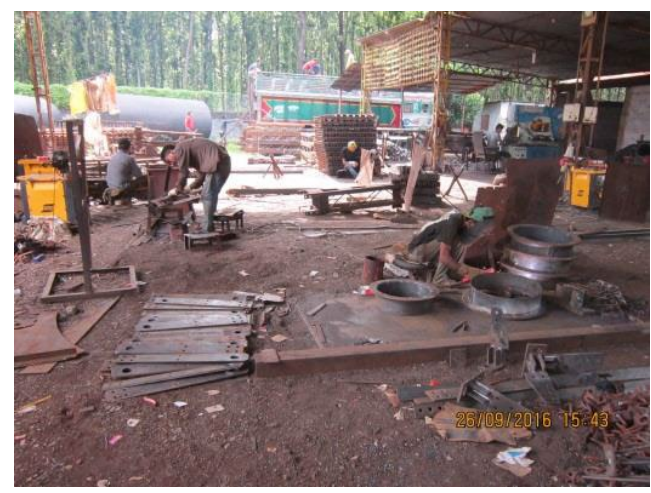

(a)

placed in trolley (wheelbarrow) (Fig 4b). The trolley was then used to move the parts to the next process. This resulted in 4 man-hours being saved in a day besides improving tidiness of the workplace.

The investment made was NPR 70,000 and the annual savings from man day reduction was NPR 120,000. The payback was around 7 months.

\subsubsection{Installation of Recuperator}

The case study company is a reheating and rolling unit in Rupandehi district. The hot flue gas from the furnace was being directly released to the environment (Fig 5a). The flue gas temperature and composition were monitored; the temperature of the flue gas was around $500^{\circ} \mathrm{C}$ indicating significant energy loss.

Based on the recommendations, the company installed a recuperator to utilize heat energy from the hot flue gas to pre-heat combustion air (Fig 5b). The hot air ducts were suitably insulated. As a result, the inlet air temperature for combustion increased from $30^{\circ} \mathrm{C}$ to $300^{\circ} \mathrm{C}$ thus saving 182.3 t of coal per annum. The investment made was NPR $1,000,000$ and the annual savings being NPR 3,646,000. The payback was around 4 months.

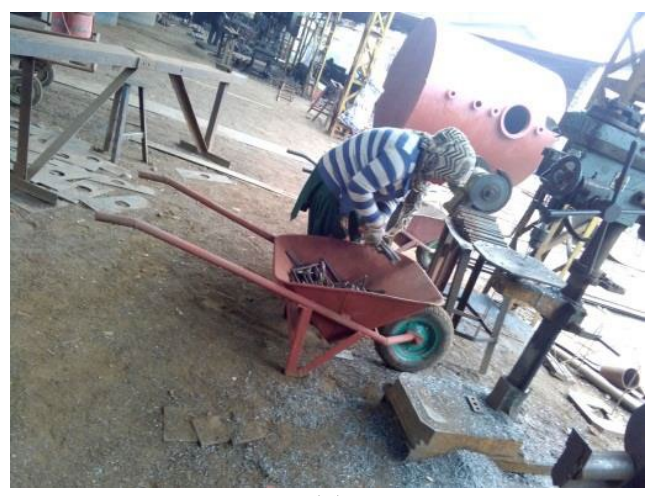

(b)

Figure 4: (a) Before: parts lying on floor and moved manually (b) After: parts placed in trolley for moving to next process

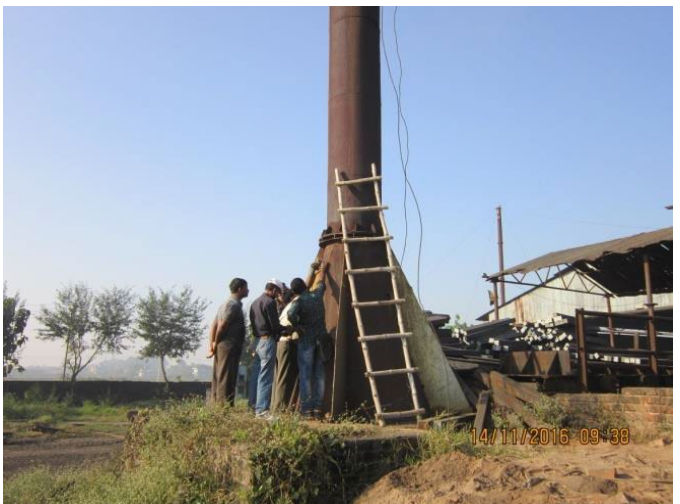

(a)

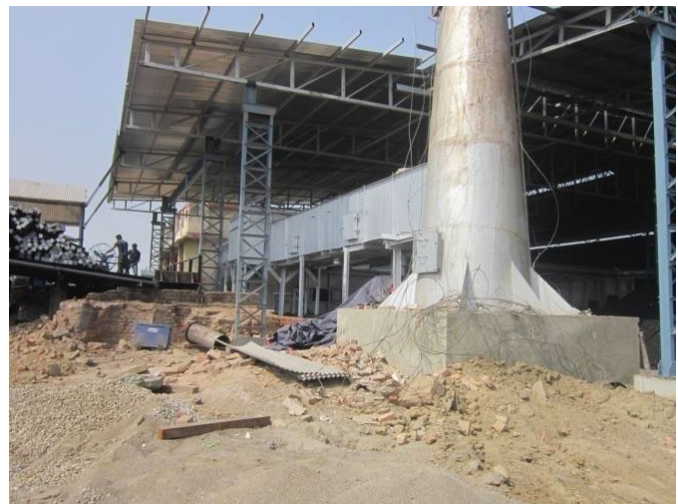

(b)

Figure 5: (a) Before: monitoring of flue gas before installation of recuperator (b) After: after installation of recuperator 


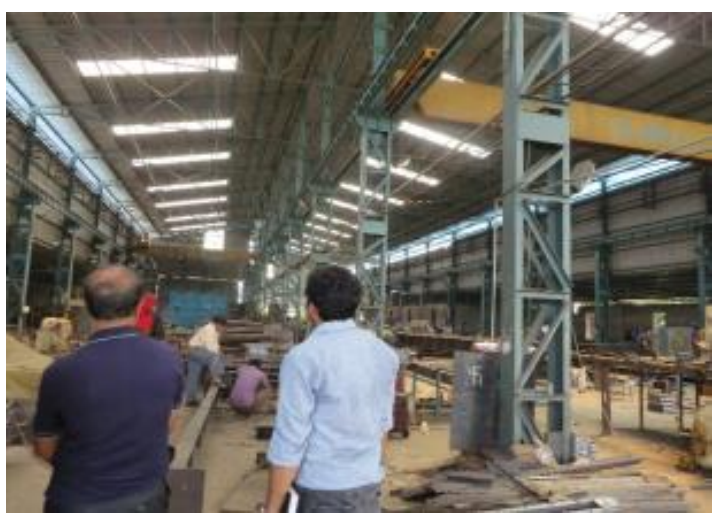

(a)

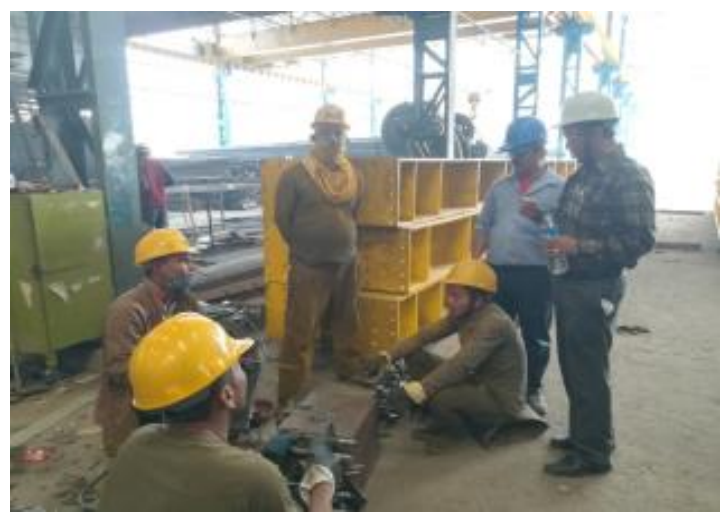

(b)

Figure 6: (a) Before: PPEs (helmets) not used in the shop floor (b) PPEs (helmets) used by all in the shop floor

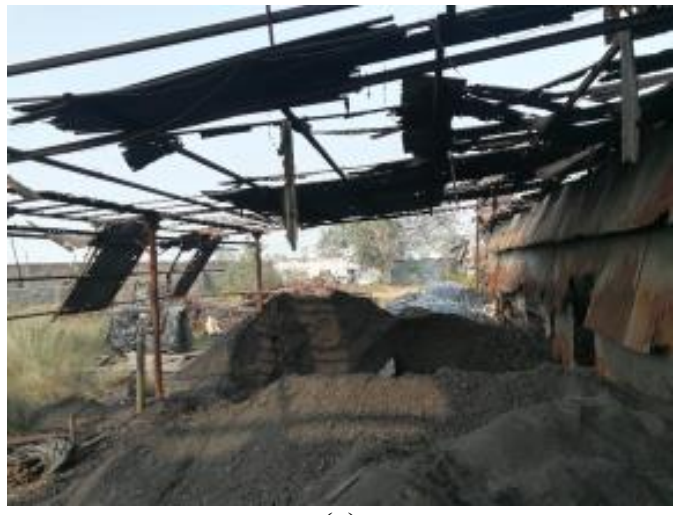

(a)

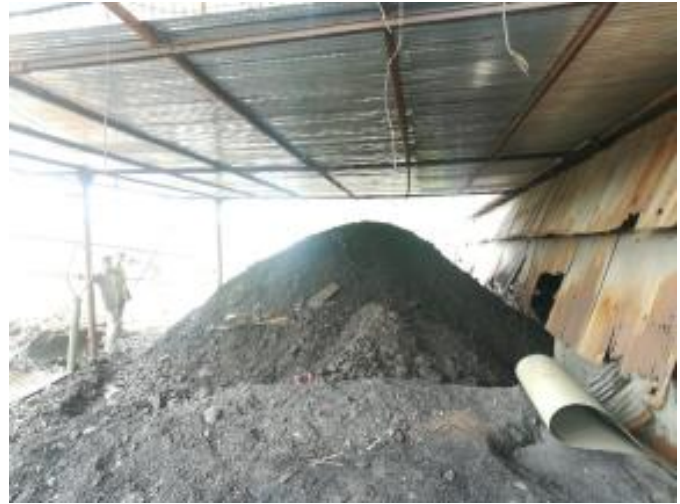

(b)

Figure 7: (a) Before: damaged roof of coal storage shed (b) After: coal stored under the repaired roof

\subsubsection{Use of Personal Protective Equipment}

This industry located in Morang district manufactures GI pipes, black pipes and fabricated products using Mild Steel (MS) sheets and plates as raw materials. The workers in the shop floor did not use Personal Protective Equipment (PPE) like helmets, boots and masks while working even though there is high risk of injury during work (Fig 6a).

During RECP awareness training, workers were made aware of the necessity of using PPE while working. Use of helmets has been made compulsory in the shop floor for everyone including visitors (Fig 6b). The color of helmets has been differentiated as yellow for shop floor workers, blue for supervisors, and white for company management and red for visitors. This has created a safer working environment and working discipline. The investment made was NPR 48,700.

\subsubsection{Proper Storing of Coal}

This rolling industry is located in Bara district. It manufactures MS section items and ThermoMechanically Treated (TMT) bars using ingots and miss- rolls from other industries as the raw material and consumes significant amount of coal as fuel. The coal was stored in a shed with a damaged roof (Fig 7a). This exposed the coal to sun, rain and wind. Also, the moisture in coal led to higher consumption and the coal took longer time to burn.

Based on the recommendations, roof of the coal storage shed was repaired (Fig 7b). This kept the coal dry and there was less contamination from dust leading to higher burning efficiency. This resulted in savings of NPR 560,000 (25.5 $\mathrm{t}$ of coal) with the investment of NPR 150,000 for the construction resulting in a payback period of 4 months.

\subsubsection{Saving of Welding Rods}

This is a fabrication unit located in Kaski district that manufactures structures, machines and auto parts using MS, Stainless Steel (SS) and aluminium sections as raw materials. The annual consumption of the welding rod is $3,365 \mathrm{~kg}$. The leftover welding rods were long (up to 50 $\mathrm{mm})$ and $1,500 \mathrm{~kg} /$ year of material was left-over. These long left over welding rods were discarded (Fig 8a). The main cause of such leftover was due to welding at not 
reachable places with short welding rods and negligence of the welder. The leftovers were scattered and not collected for reuse. Only some of the waste welding rods were collected and sold to the scrap collector (around 468 $\mathrm{kg} /$ year sold at NPR 20/kg).

An awareness program on attitude change and good operating practices was conducted. A return policy of the leftover welding rods to store before issuing new welding rod was developed. The number of new welding rods issued was the same as the number of leftovers handed in. Holders for welding rods with two partitions (one bigger partition for the new welding rods and smaller partition for temporary storing of used leftover welding rods) was designed and developed (Fig 8b). The welders started to maximize the use of welding rods and the leftover was reduced to an average of $25 \mathrm{~mm}$ material. The collection of the used welding rods increased to $936 \mathrm{~kg} /$ year. Around $90 \%$ of the used welding rods are being collected now. Besides material savings, overall tidiness of the workplace has also improved.

This measure resulted in saving of NPR 76,000 (reduction of $564 \mathrm{~kg}$ of welding rod per annum) with an investment of only NPR 2,000 for the storage holder resulting in immediate payback.

\subsubsection{Reducing Operating Pressure of Compressed Air}

Located in Bara District, this unit produces Corrugated Galvanized Iron (CGI) sheets and colour coated sheets. The case relates to compressed air for the Colour Coating Line (CCL). The set pressure of compressed air in a 22$\mathrm{kW}$ compressor was 6.5 to $7.5 \mathrm{bar}$, whereas only around 5 bar is required for operation of the machines. The high pressure setting was leading to high energy consumption by the compressor (Fig 9a).

The operating pressure range for the compressed air was reduced to 5 to 6 bars (Fig 9b). All the equipment using compressed air continued to operate smoothly at this lower pressure setting. Reduction in operating pressure reduced energy consumption by the compressor.

This intervention resulted in annual saving of NPR 59,000 due to savings in electricity $(5,900 \mathrm{kWh})$ with no investment resulting in the immediate payback.

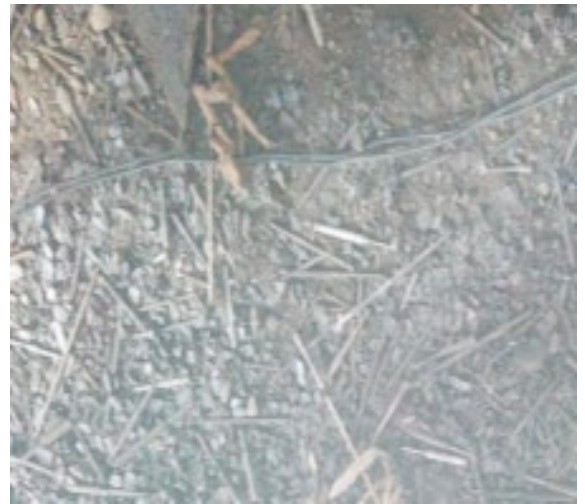

(a)

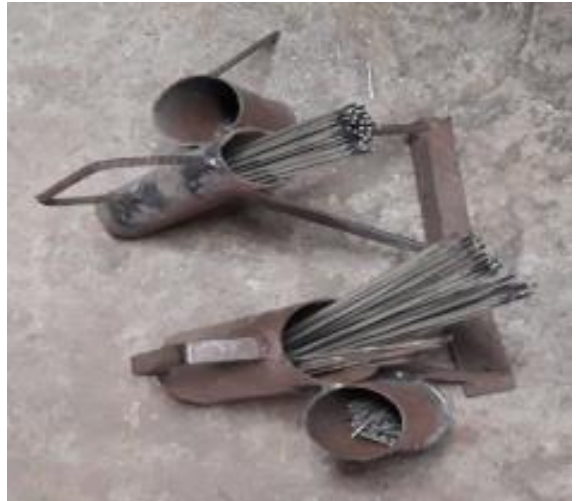

(b)

Figure 8: (a) Before: pieces of lefover welding rods were discarded (b) After: holder for collecting used and new welding rods
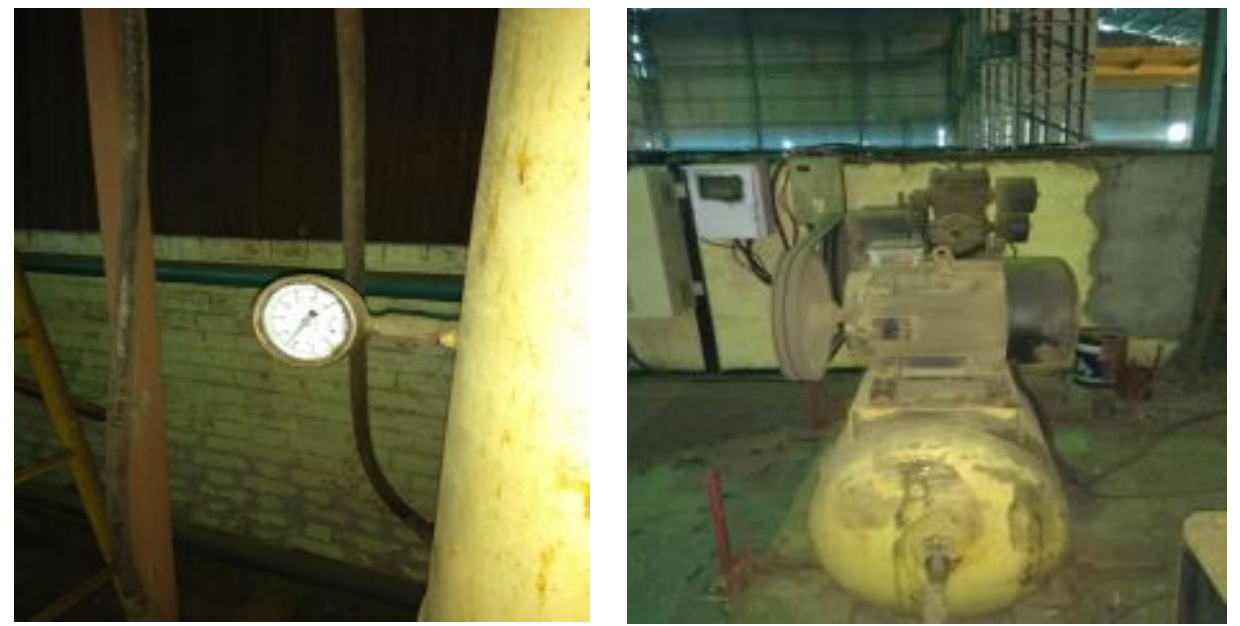

Figure 9: Compressed air receiving tank and compressor with reduced working pressure setting 


\section{$4 \quad$ Summary}

This work showcases some typical examples of RECP implementation in the metal sector industries in Nepal. It is demonstrated that significant savings in energy and materials can be achieved even with low/no cost measures. Feedback from owners and top management of the participating industries has been positive. The next steps involve continuing engagement with the participating industries to implement additional RECP measures and consolidating the overall savings achieved in these locations.

\section{Acknowledgments}

This work was co-funded by the European Commission under the EU SWITCH Asia program for the project "Resource efficient supply chain for metal products in buildings sector in South Asia (METABUILD)" contract number DCI-ASIE/2015/371-143). We would like to thank Chamber of Industries Morang (CIM), Butwal Chamber of Commerce and Industries (BuCCI), Butwal; Siddharth Chamber of Commerce and Industries (SCCI), Bhairahawa; Birgunj Chamber of Commerce and Industries (BiCCI), Birgunj for their support to conduct Management Commitment Seminars and inviting and motivating their members to participate in the Project activities.

\section{References}

[1] GIZ/NEEP, 2012: Baseline Study of Selected Sector Industries to assess the Potentials for more efficient use of energy.

[2] http://www.cpc.at/ (accessed May 12, 2018)

[3] http://www.ecoprofit.com/ (accessed November 17, 2016)

[4] Altenburger J., Dielacher Th., Eder P., Ferner H., Fegerl M., Fresner J., Gelinek O., Kogler A. Jantschgi J., Nussbaumer M., Russegger B., Schnitzer H., Schauer K., Sebesta B., Seiler J., Sprenger F., Widenmeyer H., 1994. Ecoprofit-Styria-prepare thirteen pollution prevention case studies in the Styrian industry. Journal of Cleaner Production 2 (3-4), 219-221 